\title{
Médiévales
}

Langues, Textes, Histoire

59 | automne 2010

Théâtres du Moyen Âge

\section{Fabrizio NEVOLA, Siena. Constructing the Renaissance City, New Haven/Londres, Yale University Press, 2007, 303 p.}

Didier Boisseuil

\section{(2) OpenEdition}

Journals

Édition électronique

URL : https://journals.openedition.org/medievales/6178

DOI : 10.4000/medievales.6178

ISSN : 1777-5892

Éditeur

Presses universitaires de Vincennes

\section{Édition imprimée}

Date de publication : 31 décembre 2010

Pagination : 197-199

ISBN : 978-2-84292-267-2

ISSN : 0751-2708

Référence électronique

Didier Boisseuil, «Fabrizio nevola, Siena. Constructing the Renaissance City, New Haven/Londres, Yale University Press, 2007, 303 p. », Médiévales [En ligne], 59 | automne 2010, mis en ligne le 10 mars 2011, consulté le 22 avril 2022. URL : http://journals.openedition.org/medievales/6178 ; DOI : https:// doi.org/10.4000/medievales.6178

Ce document a été généré automatiquement le 22 avril 2022.

Tous droits réservés 


\title{
Fabrizio NEVOLA, Siena. Constructing the Renaissance City, New Haven/ Londres, Yale University Press, 2007, 303 p.
}

\author{
Didier Boisseuil
}

1 Sienne n'est pas seulement une cité médiévale appréciée des touristes, c'est aussi une ville façonnée par la Renaissance, comme sa rivale, la puissante Florence, ainsi que nous le rappelle magistralement Fabrizio Nevola dans un ouvrage dense et remarquablement bien illustré. L'auteur montre, en effet, comment, au cours du Quattrocento, l'apparence de la cité s'est progressivement transformée et combien des formes architecturales nouvelles se sont imposées dans le paysage urbain. Il s'attache non seulement à révéler dans le détail les traits singuliers d'un langage classicisant propre aux Siennois, mais aussi la nature des nouvelles réalisations, qu'elles soient publiques (fontaines, chapelle, etc.) ou privées (palais, loggia, etc.).

2 Son étude - empreinte d'une belle connaissance de la culture et de la société siennoises - s'attache surtout à désigner les choix, les stratégies, les comportements des élites citadines et notamment du petit groupe d'oligarques qui, à la fin du $\mathrm{XV}^{\mathrm{e}}$ siècle, guidés par Pandolfo Petrucci (1512), s'empare de la République. Car Sienne n'échappe pas à la mise en place d'un régime princier, même s'il fut plus tardif et plus bref qu'à Florence.

3 L'auteur décrit les principales causes de ces changements progressifs : la nécessité de reconstituer l'habitat sur les parcelles abandonnées après les épidémies; la volonté des régimes populaires successifs de remanier ou concevoir des résidences pour accueillir avec faste des souverains - les empereurs Sigismond de Luxembourg (en 1432-1433) ou Frédéric III (1453), les papes Martin V (1423), Eugène IV (1443) - et les princes étrangers - comme le duc Alphonse de Calabre -, tour à tour alliés et adversaires de l'État siennois auxquels ils cherchaient à plaire. Le long séjour du pape Pie II (1458-1464) fut un moment décisif, puisque le souverain pontife suscita plusieurs réalisations d'envergure (deux palais et une loggia) et contraignit la commune à déployer une 
véritable politique d'embellissement de la cité confiée à un office particulier celui de " l'Ornato ». Le souhait de quelques citoyens enrichis et comblés de faveurs impériales (comme les Bichi ou les Pecci) de se distinguer de leurs compatriotes suscita aussi la construction de nouveaux palais adaptés aux goûts et aux besoins du jour, qui servirent de lieux d'accueil aux suites princières: l'architecture devenant une affaire civique mais aussi économique puisque ces palais représentaient des investissements négociables, pivots de stratégies financières et sociales. Fabrizio Nevola met aussi en lumière l'importance dans ces transformations urbaines d'un milieu humaniste - guidé par le cardinal Francesco Todeschini-Piccolomini et désireux d'affirmer la prépondérance d'une oligarchie éclairée dans cette "cité populaire » - et souligne le rôle d'Agostino Patrizi qui, dans son De origine et vetustate urbis Senae (1480), s'efforça de donner à la cité un passé digne de son éclat nouveau, justifiant ainsi le recours à l'Antiquité romaine, soutenant le rapprochement avec la cité éternelle.

Les travaux entrepris révèlent un goût prononcé pour des formes classiques (surtout à partir de la visite du pape Piccolomini), distinctes de celles adoptées à Florence, qui ne rompent pas toujours avec les traditions gothiques. Elles sont réalisées par des architectes de talent (Antonio Federighi, Giuliano da Maiano), des maçons (lombards) expérimentés. Les réalisations se situent sur les principaux axes routiers et notamment la voie qui, traversant la cité de part en part, conduit les voyageurs jusqu'à Rome (le tronçon urbain de la «via francigena»), sur la place du Campo (avec notamment la fontaine de Jacopo della Quercia) ou sur quelques bâtiments plus marginaux convertis en lieu de représentation comme le couvent Sainte-Marthe devenu résidence privilégiée des souverains étrangers. Surtout, Fabrizio Nevola montre brillamment comment, à la fin du siècle, les efforts déployés par les citoyens de l'entourage de Pandolfo Petrucci se concentrent sur un quartier proche de la cathédrale - la via del Capitano - qui devient en quelques années l'artère la plus prestigieuse de Sienne, polarisant l'activité mondaine (voire publique) de la cité. Ainsi, à travers le bâti médiéval et le lassis des ruelles, Sienne se pare de bâtiments nouveaux qui, sans altérer considérablement l'image d'une ville médiévale, lui confèrent une modernité incontestable. 